\title{
Indidence of tuberculosis in children in the state of São Paulo, Brazil, under spatial approach
}

Taís Siqueira Venâncio ${ }^{1}$

Tássia Soldi Tuan ${ }^{1}$

Luiz Fernando Costa Nascimento ${ }^{1}$

${ }^{1}$ Departamento de Medicina, Universidade de Taubaté. Av. Tiradentes 500, Jardim das Nações. 12030180 Taubaté SP Brasil.

tais.venancio@hotmail.com

\begin{abstract}
The aim of this study was to identify spatial patterns in the incidence of childhood tuberculosis in cities in the state of São Paulo. An ecological and exploratory study was carried with data on new cases of tuberculosis in children 0 to 14 years old for the period 2001 to 2005 and from 2006 to 2010, obtained from DATASUS. Data of the population of this age group were collected and raised rates per 100000 inhabitants. Moran's index (I) was calculated for both periods. Thematic maps with the rates and its difference besides Moran maps, maps with Kernel densities, educational level and income were constructed using using TerraView software. The average rates were 3.23 / 100000 inhabitants in the first period (2881 cases reported) and 2.13 / 100000 inhabitants in the second period (2513 cases reported); the Moran index in the first period was $I=0.03$ ( $p$ $=0.16)$ and $I=0.06(p=0.01)$ in the second $p e$ riod; the thematic map identified 462 municipalities with higher interest rates in the second period; the kernel map identified higher density rates in the metropolitan region of São Paulo, west coastal cities and in the first period and the second period, the metropolitan region of São Paulo and coastal cities. The data presented in this study provide informations to local and regional managers to implement policies for tuberculosis control.
\end{abstract}

Key words Tuberculosis, Spatial analysis, Geographic information systems, Child's health 


\section{Introduction}

Tuberculosis (TB) is a chronic infectious disease that has long affected humanity, and remains a serious public health problem to this day. With the development of new and potent chemotherapy in the 1960s it was thought that the disease would have a very effective control ${ }^{1}$.

Nowadays, two billion people (one third of the world population) are infected with M. tuberculosis. Among of these, eight million will develop the disease and two million die each year ${ }^{2}$. Brazil is among the 22 countries responsible for $82 \%$ of TB cases in the world, being the thirteenth in absolute numbers and comprises $35 \%$ of the cases reported in the Americas region ${ }^{3}$. Brazil has an annual incidence of 43 cases per 100000 inhabitants (85000 new cases/year), an incidence rate of positive pulmonary form of 26/100 thousand (49 000 new cases/year) and the mortality rate of 2.6/100 000 inhabitants (5000 deaths/year) according to WHO estimates ${ }^{3}$. In the Southeast region about 33000 cases were reported in 2006; and the State of São Paulo had the highest number of cases in the same year, with about 15000 new cases ${ }^{4}$.

Five hundred and thirty thousand new cases of TB cases in children up to 15 years old were estimated by WHO in 2012 worldwide, equivalent to $6 \%$ of all cases, with 174,000 deaths from this disease $^{5}$. In Brazil, $15 \%$ of cases notified TB cases occur in children under 15 years old ${ }^{6,7}$.

The number of cases of TB in children is directly related to the prevalence of the disease in adults, reflecting the continued transmission in the community. Thus, the presence of the disease in children should be seen as a sentinel to the public health, because it refers to a recent infection due to contact with contagious adults 8 .

Geo referencing of health events is very important for analysis and evaluation of risks to the public health and the use of thematic maps can explore local and regional determinants of certain events and establish associations between these events and determinants, and evaluate interventions ${ }^{9-11}$.

The aim of this study was to identify the spatial pattern of incidence of tuberculosis in children in the municipalities in the state of São Paulo in two periods.

\section{Methodology}

An ecological and exploratory study was carried out with data on the incidence rate of $\mathrm{TB}$ in children 0-14 years old in the municipalities in the state of São Paulo. These data were obtained from Datasus website covering the period from 2001 to 2010, and was divided into two periods: 2001-2005 and 2006-2010. Population data of this age group were collected and incidence rates of childhood TB cases per 100,000 inhabitants were calculated. The digital base of municipalities was obtained from Brazilian Institute of Geography and Statistics (IBGE) ${ }^{12}$.

Moran's index, with corresponding $\mathrm{p}$-value was calculated; this index calculates the spatial correlation of the rates obtained and their values range from -1 to +1 . Values near zero indicate absence of spatial autocorrelation, the events are at random. The closer to 1 , the greater the similarity between neighbors and negative values mean that are dissimilar ${ }^{13}$.

Difference in incidence rates of childhood TB was obtained by subtracting the data of the first period incidence, 2001-2005, from the second period values, 2006 to 2010. Mean values for each period were compared using Student's $t$ test. Values of the population aged 15 or older who has a high educational level were used to create rates that indicate the proportion of the population with this educational level; proportion values of people who earn less than half the minimum wage household income were also analyzed. These data were obtained from Datasus website.

Kernel estimator created the density map of the incidence rates of TB in children 0-14 years old. The method is based on calculations of the cases density (number of cases per area), producing a surface where areas with probabilities closer cases at higher risk, whose denominator for rate is in another layer, the density of people (inhabitants per area or population density) also as continuous surface ${ }^{13}$. Kernel density maps, with incidence rates of $\mathrm{TB}$ in children on both periods, were built with 150 columns, quartic function, density calculation and adaptive radius. Both maps were categorized according to density levels vary with color and tonality.

Thematic maps were constructed with the incidence rates of TB in children; with differenc- 
es in incidence rates, showing where there was a worsening of the incidence rates of TB in children and with rates of education and income. Moran's map identifying municipalities that deserve more attention from administrators was also constructed.

Terra View 4.2.2 software released by INPE was used. Alpha $=5 \%$ was the level of significance.

\section{Results}

Two thousand eight hundred eighty-one new cases of childhood TB were identified in the period 2001-2005, in the cities of the São Paulo State; these data represent an average incidence rate of 3.23 cases $/ 100,000$ inhabitants $(\mathrm{SD}=6.56$, ranging between 0.00 and 67.70); 2513 new cases were identified in the period 2006-2010, in 645 municipalities of São Paulo; these data represent an average incidence of 2.13 cases (standard deviation $=3.69$ ranging between 0.00 and 22.95)/100,000 inhabitants. Comparing these rates, they are significantly different ( $\mathrm{p}$-value $<0.01$ )

Thematic maps of the rates in the first and second period are in Figure 1A (2001 to 2005) and 1B (2006-2010), respectively. In the first period, Figure 1A, municipalities located primarily in the Paraíba Valley, coastal cities, São Paulo metropolitan region, Central region of the state and far west region, where rates of childhood TB are high, can be observed. The Northwest region had lower rates. In the second period, Figure 1B, there was little change, and it is possible to observe a decrease in the incidence rates of childhood TB in regions of the Paraíba Valley, coastal cities, São Paulo Metropolitan Region, Central Region and the far west, but there was an increase in these rates in the northern state, on the border with the state of Minas Gerais.

The difference in incidence rates of childhood TB, subtracting the data of the first period of the values in the second period, identified cities where there was an increase in these rates. This difference in rates did not show any significant spatial autocorrelation because $\operatorname{Im}=-0.01$ ( $p$-value $=0.28)$. Large number of municipalities (462) showed an increase in rates, but those in the metropolitan region of São Paulo, municipalities that border the Dutra Highway and coastal cities (183) decreased (Figure 2).

The Kernel maps in Figure 3A and 3B show a visual comparison analysis of the incidence rates densities of childhood TB in the periods 2001-

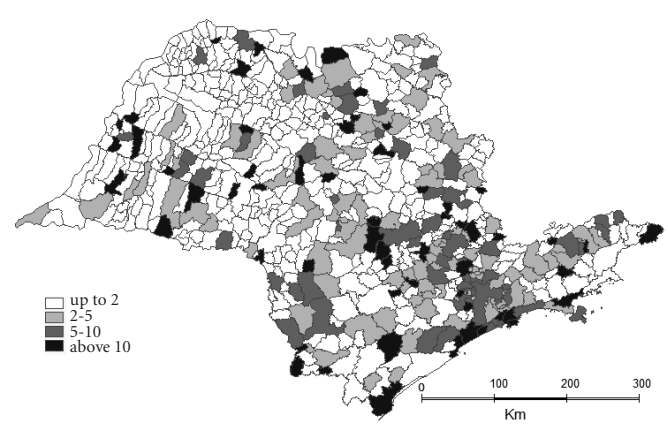

Figure 1A. Thematic map with incidence rates of tuberculosis in children 0-14 years old in the period 2001-2005, São Paulo State, 2001-2010.

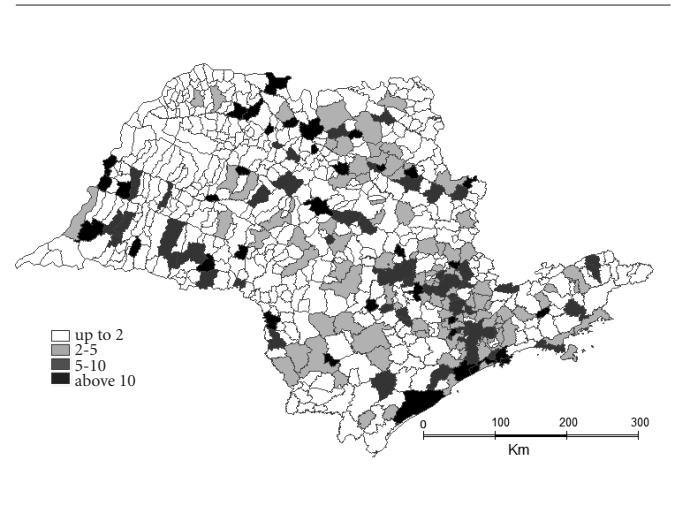

Figure 1B. Thematic map with incidence rates of tuberculosis in children 0-14 years old in the period 2006-2010, São Paulo State, 2001-2010.

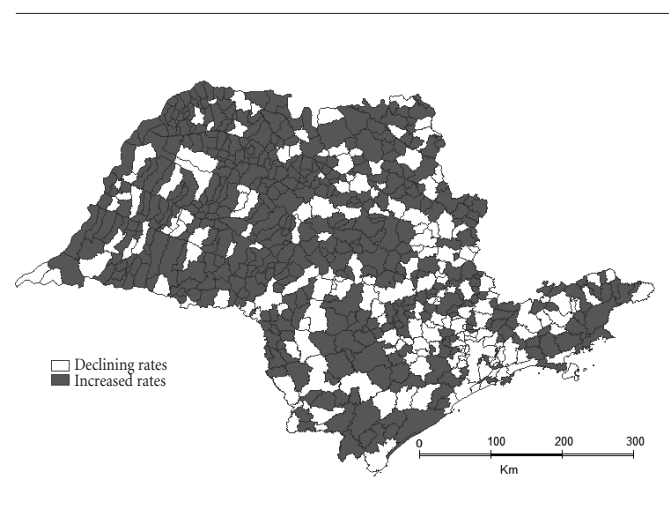

Figure 2. Difference in incidence rates of tuberculosis in children 0-14 years old, São Paulo State, 2001-2010.

2005 and 2006-2010, and in the first, a greater density was identified in the Metropolitan Re- 


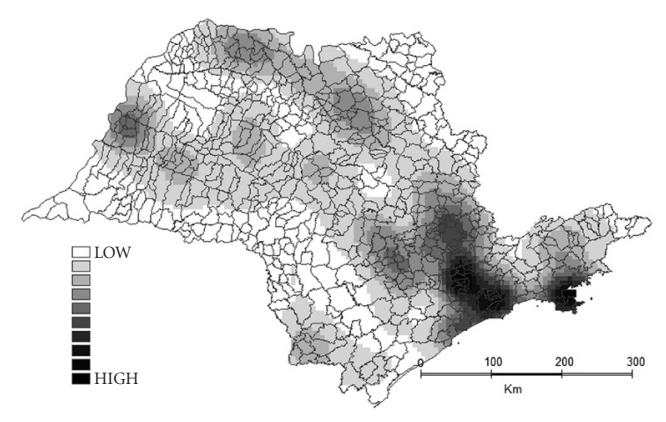

Figure 3A. Kernel Maps of incidence of tuberculosis in children 0-14 years old in the period 2001-2005, São Paulo State, 2001-2010.

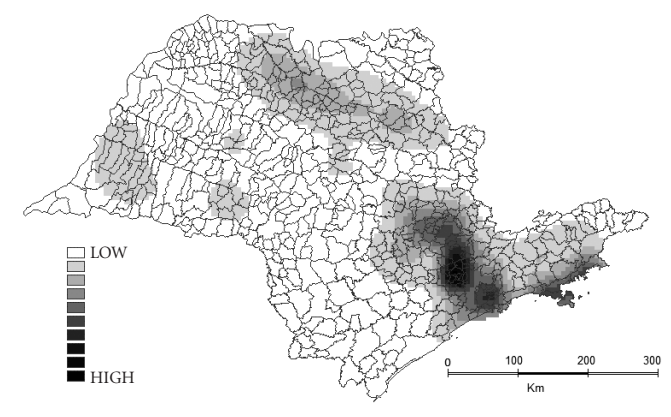

Figure 3B. Kernel Maps of incidence of tuberculosis in children 0-14 years old in the period 2006-2010, São Paulo State, 2001 -2010.

gion of São Paulo, and the far west; in the second, the high density remained only on the coastal cities and in the Metropolitan Region of São Paulo.

Moran's index calculated for the first time presented an $\operatorname{Im}=0.03(p$-value $=0.16)$, showing no significant spatial autocorrelation. Moran's index calculated for the first time presented Im $=0.03(\mathrm{p}$ - value $=0.16)$, showing no significant spatial autocorrelation. Ten cities with priority intervention were identified using Moran's map that identifies areas that deserve more attention (map not shown); these show high rates, and are located in the Metropolitan Region of São Paulo, coastal cities and the far west.

In the second period, 2006-2010, Moran's index showed $\operatorname{Im}=0.06(\mathrm{p}$-value $=0.01)$ with a positive spatial autocorrelation, even with Im small value, this proved significant because it has a large number cities. Moran's map (map not shown) identified 33 municipalities that must be investigated, located in the Metropolitan Region of São Paulo, coastal cities and in the far North.

The proportion values of the population aged 15 or older who presents high education level were placed on a map (map not shown); in both periods cities with higher rates and higher educational level are located in the Metropolitan Region of São Paulo, coastal cities, Paraíba Valley and upstate, following the edges of Dutra, Anhanguera and Bandeirantes highways; these cities have over $30 \%$ of the population with high educational level.

In the first period, largely on the state of São Paulo there were more than $50 \%$ of municipalities with household income up to half minimum wage. The metropolitan region of São Paulo, municipalities that border the Dutra Highway and coastal cities had better income, with up to $40 \%$ of the cities with low income according to the map (map not shown). In the second period, this region had $30 \%$ of cities with low income. The rest of the state had rates of $40 \%$ to more than $50 \%$ of the cities with household income up to half minimum wage (map not shown).

\section{Discussion}

This study identified spatial pattern for the distribution of rates of childhood TB in the state of São Paulo in individuals up to 14 years old; it was also possible to identify cities where there was an increase in these rates and also those cities where there was a decrease.

This is the first study carried out in the state of São Paulo using the tools of spatial analysis with data on incidence of tuberculosis in children up to 14 years old. The disease was approached in two periods. This approach, mapping disease, has been an important tool in the field of public health with advances in analytical techniques that have been developed in recent years ${ }^{11,14,15}$.

The Emergency Plan for Tuberculosis Control was released in 1996, but there were difficulties in the decentralization process and for expanding basic network since the formalization of the program in 1999 The current National Tuberculosis Control Program (NTCP) was approved and placed on the agenda public policies in Brazil only in $2004^{16,17}$. Comparing the two periods there was a decrease in the incidence rates of TB in children from the first to the second 
period (3.23 for 2.13 cases/100 000 inhabitants), possibly due to the implementation of the current NTCP and strengthening the primary care through access to diagnosis and treatment, which may have contributed to the decline in incidence rates of TB in the state of São Paulo?.

Rates found in this study for the first and second period are close to those found in the state of Minas Gerais (3.52 to 3.35 cases/100 000 inhabitants). On the other hand, these rates are lower than the rates found in the states of Rio de Janeiro (14,98-13.28 cases/100 000 inhabitants) and Bahia (7.63 to 6.33 cases/100 000 inhabitants $)^{18}$. In a study of 1996 data from the São Paulo Paraíba Valley, the cities showed an incidence in this age group of 10.4/100 000 inhabitants $^{18}$.

The thematic map with the difference between the rates according to the periods showed an increased incidence of childhood TB in 462 cities in the state in the second period, and lower rates occurred in 183 cities. Despite the decrease in the number of cases and also lower rates of TB incidence in the second period, there was an increase in this rate in most cities; however the decrease numerically exceeds the increase in incidence rates of $\mathrm{TB}$ in this age group with the greatest impact on reducing the rates that increase them.

Nuclei of higher concentration of TB cases were identified by Kernel estimator, and are located in the metropolitan region of São Paulo, coastal cities, Western and Northern State. In the second period, with lower rates, there was a change in the concentrations of cases, as evidenced by the Kernel estimator, but remaining high in the metropolitan region of São Paulo and coastal cities, possibly because they are areas of great expansion and human settlement.

In the first period, although Moran rate's presented absence of significant spatial autocorrelation, 10 cities were identified with a high priority for intervention by managers, and are located in the metropolitan region of São Paulo, coastal cities and two in the far west. In the second period there is positive spatial autocorrelation, the map showed 33 cities with high priority for intervention, located in the Metropolitan Region of São Paulo, coastal cities, two in the far west and two in the far north. Through this analysis, it was possible to identify clusters of cities that should be under investigation for decrease rates of $\mathrm{TB}$ in childhood.

In this study the distribution of incidence rates and the Kernel density of the highest rates were in cities with better socioeconomic con- ditions in the state of São Paulo. Inequalities in housing, income distribution and access to education affect the disease in geographic areas characterized by poverty pockets inside these counties and these unjust differences place groups at a disadvantage in relation to the opportunity to be and stay healthy ${ }^{19}$.

Schooling in people's lives reflected an access to knowledge and ability to understand disease prevention and prescribed therapy. The low income and low educational level configure a set of unfavorable socioeconomic conditions ${ }^{20}$. However, it is interesting to note that the regions which have higher incidence rates of tuberculosis in children do not coincide with areas of low income and low education in the state of São Paulo, but in places where there are better conditions and more access to education.

This fact can be explained because to notify TB is compulsory; thus, in regions where there are better wage conditions there may be better access to health care. Whereas in regions with low incidence of TB in childhood, the disease is not being notified correctly. Unemployment, low education level and low income are factors that increase vulnerability to $\mathrm{TB}$, so, that may hinder access to health services to obtain a correct diagnostic ${ }^{4}$. The fact that higher rates in those cities with better income and schooling exist would be due to improved care in health facilities that would count with more experienced technical personnel who "think" about tuberculosis, and with better infrastructure, could make more diagnosis of childhood TB.

The data source used - National Disease Information Agency (SINAN) can be included as a possible limitation of this study because it may contain errors pointing out diagnosis, despite being an official, stable and reliable source and widely used in technical and scientific papers. Ecological studies do not have individual information on exposure and disease, and thus one cannot evaluate the comorbidities ${ }^{11}$. It was difficult to compare the findings of this study with others because there are few studies with the same way of approach on tuberculosis in children by using the state as an area study.

The epidemiological situation of TB in children is another possible limitation. Difficulties with access to health services and diagnosis should also be considered. Underreporting of cases of TB in children may occur due to the difficulty to confirm the diagnosis of TB in this age group, since $80 \%$ of childhood cases are negative on sputum examination ${ }^{8}$. 
This study provided information about the spatial distribution of childhood TB new cases in the cities of São Paulo, and it identifies cities that should require intervention of municipal and state management through decentralization of TB for primary health care and increase coverage of family health strategy, since childhood TB refers to infection due to recent contact with contagious adults. If the Program for Tuberculosis Control does not diagnose and treat early tuberculosis in adults, it will not be reduced in children.

\section{Collaborations}

TS Venâncio, TS Tuan and LFC Nascimento participated equally in all stages of preparation of the article.

\section{Aknowledgments}

TS Venâncio thanks São Paulo Research Foundation - FAPESP for the scholarship grant. 


\section{References}

1. Leite AMT. Caracterização clínica-epidemiológica dos pacientes com diagnóstico de tuberculose atendidos em um serviço de referência em Maceió, Alagoas [tese]. Rio de Janeiro: Universidade Candido Mendes; 2009.

2. Heck MA, Costa JSD, Nunes MF. Avaliação do programa de tuberculose em Sapucaia do Sul (RS): indicadores, 2000-2008. Cien Saude Colet 2013; 18(2):481-488.

3. World Health Organization (WHO). Global Tuberculosis Control 2011: WHO Report 2011. Geneva: WHO; 2011.

4. Oliveira GP, Pinheiro RS, Coeli CM, Barreira D, Codenotti SB. Uso do sistema de informação sobre mortalidade para identificar subnotificação de casos de tuberculose no Brasil. Rev bras epidemiol 2012; 15(3):468477.

5. World Health Organization (WHO). Global Tuberculosis Control 2013: WHO Report 2013. Geneva: WHO; 2013.

6. Maciel ELN, Dietze R, Silva RECF, Hadad DJ, Struchiner CJ. Avaliação do sistema de pontuação para o diagnóstico da tuberculose na infância preconizado pelo Ministério da Saúde, Brasil. Cad Saude Publica 2008; 24(2):402-408.

7. Alves R, Sant'Anna CC, Cunha AJLA. Epidemiologia da tuberculose infantil na cidade do Rio de Janeiro, RJ. Rev Saude Publica 2000; 34(4):409-410.

8. Sant'Anna CC, Hijjar MA. Recente contribuição da Organização Mundial de Saúde para o controle da tuberculose na infância. Rev Saude Publica 2007; 41(1):117120.

9. Montechi LN, Coelho DMM, Oliveira CAR, Campelo V. Distribuição espacial da tuberculose em Teresina, Piauí, de 2005 a 2007. Epidemiol Serv Saúde 2013; 22(3):475-482.

10. Sales CMM, Figueiredo TAM, Zandonade E, Maciel ELN. Análise espacial da tuberculose infantil do Estado do Espírito Santo 2000 a 2007. Rev da Sociedade Brasileira de Medicina Tropical. 2010; 43(4):435-439.

11. Nascimento LFC, Batista GT, Dias NW, Catelani CS, Becker D, Rodrigues L. Análise espacial da mortalidade neonatal no Vale do Paraíba, 1999 a 2001. Rev Saude Publica 2007; 41(1):94-100.
12. Instituto Brasileiro de Geografia e Estatística (IBGE). Dowloads. [cited 2014 Mar 10]. Disponível em: http:// downloads.ibge.gov.br/downloads_geociencias.htm

13. Brasil. Ministério da Saúde (MS). Secretaria de Vigilância em Saúde, Fundação Oswaldo Cruz (Fiocruz). Introdução a Estatística Espacial para Saúde Pública. Brasília, Rio de Janeiro: MS, Fiocruz; 2007. (Série GEO vol. 3).

14. Almeida MCS, Gomes CMS, Nascimento LFC. Analise espacial da mortalidade neonatal no estado de SP 2006 a 2010. Rev Paul Pediatr 2014; 32(4):374-380.

15. Mukai AO, Nascimento LFC, Alves KSC. Análise espacial das internações por pneumonia na região do Vale do Paraíba (SP). J bra. pneumol 2009; 35(8):753-758.

16. Santos J. Resposta brasileira ao controle da tuberculose. Rev Saude Publica 2007; 41(Supl. 1):89-93.

17. Brasil. Ministério da Saúde (MS). Secretaria de Vigilância em Saúde. Programa Nacional do Controle da Tuberculose. [cited 2014 Sep 9]. Disponível em: http:// bvsms.saude.gov.br/bvs/publicacoes/ProgramaTB.pdf

18. Brasil. Ministério da Saúde (MS). Departamento de Informações e Informática do Sistema Único de Saúde, DATASUS. [cited 2014 Mai 20]. Disponível em: http:// w3.datasus.gov.br/datasus/index.php.

19. Nascimento LFC. Childhood tuberculosis incidence in Southeast Brazil, 1996. Cad Saude Publica 2004; 20(6):1749-1752.

20. Araujo KMFA, Figueiredo TMRM, Gomes LCF, Pinto ML, Silva TC, Bertolozzi MR. Evolução da distribuicão espacial dos casos novos de tuberculose no município de Patos (PB), 2001-2010. Cad saúde colet 2013; 21(3):296-302.

Article submitted 22/07/2014

Approved 10/10/2014

Final version submitted 12/10/2014 
